\title{
Sobre a permeabilidade do léxico à pandemia: A frequência e os sentidos das palavras no discurso noticioso
}

\section{About the Effects of the Pandemic on the Lexicon: Lexical Frequency and Word Meanings in News Discourse}

Teresa DA Costa [teresa.costa@staff.uma.pt]

Universidade da Madeira, Portugal

Centro de Linguística da Universidade de Lisboa, Portugal

\section{RESUMO}

O léxico de uma língua é um corpo vivo e dinâmico, permeável a fatores extralinguísticos, que marcam a sociedade num determinado tempo e espaço. Neste trabalho, estudou-se a influência da pandemia Covid-19 no vocabulário do discurso noticioso em Portugal. O corpus discursivo analisado foi constituído por 29 sessões de um noticiário diário da televisão pública portuguesa. Fez-se a comparação entre o discurso veiculado em 2019 e em 2020, após a chegada da pandemia a Portugal. Os resultados mostram a ação do contexto pandémico sobre as palavras usadas no noticiário, no que diz respeito a variações na frequência de ocorrência dos itens lexicais e também no que concerne a sentidos metafóricos que são associados a algumas palavras, para fazer referência à doença. Os resultados são discutidos à luz da investigação já existente sobre frequência lexical e metáfora conceptual no discurso mediático.

\section{Palavras-chave}

Léxico; pandemia; frequência; metáfora; discurso noticioso

\begin{abstract}
The lexicon of a language is a living and dynamic body, permeable to extralinguistic factors, which define society in a certain time and space. This study focuses on the influence of Covid-19 pandemic on the lexicon of news discourse in Portugal. The discursive corpus was compiled with 29 sessions of a daily newscast of Portuguese public television. A comparison was made between speech broadcasts in 2019 and in 2020, after the arrival of the pandemic in Portugal. The results show an influence of the pandemic context on words used in the news, regarding variation in frequency of occurrence of lexical items and also with regard to metaphorical meanings that are associated with some words, to refer to the disease. The results are discussed in the light of existing research on lexical frequency and conceptual metaphor in media discourse.
\end{abstract}




\section{KEYWORDS}

Lexicon; pandemic; frequency; metaphor; news discourse

RECEBIDO 2021-03-25; ACEITE 2021-05-25

Este trabalho é financiado pela FCT - Fundação para a Ciência e a Tecnologia, I.P., através do Centro de Linguística da Universidade de Lisboa (UIDB/00214/2020).

\section{Introdução}

A língua, veículo de interação entre o indivíduo e o meio circundante, é um fenómeno social, permeável à influência dos acontecimentos que marcam a comunidade.

O léxico é uma das componentes da língua em que essa permeabilidade ao contexto social é mais notória. É um domínio pluridimensional "onde se caldeiam de forma dinâmica, plurivectorial e em rede [...] os mecanismos cognitivos, codificação linguística e contexto sócio-cultural e pragmático (Rio-Torto 2013: 1). O dinamismo e a plasticidade do léxico, determinados em larga medida pela realidade extralinguística, conferem-lhe um valor documental. Estudar o léxico é, assim, aceder a um testemunho do modus vivendi, das preocupações e dos anseios de uma determinada comunidade num contexto temporal específico (Tan et al. 2020).

Na sociedade do século XXI, moderna e em constante e rápida mutação, a interação com o léxico está patente particularmente no surgimento de novos vocábulos, criados para dar conta dos conceitos que vão emergindo nas diferentes áreas do conhecimento (Antunes 2012). No entanto, a influência sociocultural no léxico não se corporiza apenas nos neologismos. Ela repercute-se também nos níveis de frequência com que são usadas as palavras e nos matizes de sentidos que lhes são atribuídos. A este respeito, alguns estudos têm mostrado, por exemplo, que a ocorrência de picos de frequências lexicais e a emergência de determinadas conceptualizações metafóricas refletem vivências sociais específicas e servem diferentes propósitos comunicacionais (Silva 2013; Tan et al. 2020).

Neste século, o fenómeno social de maiores proporções vivido até o momento tem por nome Covid-19. Este neologismo foi criado pela Organização Mundial da Saúde (OMS) em fevereiro de 2020, para designar a doença provocada pelo Coronavírus SARS-COV-2 (Tan et al. 2020). Esta nova estirpe foi identificada pela primeira vez em humanos no final de 2019, na cidade chinesa de Wuhan, alastrando-se posteriormente a todo o mundo, tendo, a 11 de março de 2020, sido declarada pandemia pela OMS.

De acordo com os dados da Direção Geral de Saúde (DGS), em Portugal, os dois primeiros casos identificados foram comunicados no dia 02 de março de 2020. Nessa altura, a sociedade portuguesa olhava com preocupação o número crescente de casos em Espanha e em Itália e pedia precaução a quem regressasse desses países. Em 16 de março, foi anunciada a primeira morte em Portugal associada à pandemia, contando-se já um total de 331 infetados em todo o país. A 18 de março é decretado o Estado de Emergência, que determina o confinamento obrigatório da popu- 
lação e restrições à circulação na via pública. A 31 de março, Portugal contava já com 7443 casos confirmados e 160 mortes reportadas. Toda a atividade considerada não essencial foi encerrada e as preocupações eram crescentes, não só com o reforço da capacidade do Serviço Nacional de Saúde (SNS) e com a proteção dos indivíduos mais vulneráveis, mas também com as consequências, a médio e longo prazo, da paralisação na economia (Porfírio 2020).

Neste período, a doença Covid-19 passou a assumir um papel central no discurso expresso nas redes sociais e nos meios de comunicação social. Paralelamente, a junção do confinamento à incerteza sobre o comportamento e os efeitos do vírus deu azo à proliferação de notícias falsas, acerca de surtos, de medidas de prevenção ou de tratamentos. Neste contexto, os noticiários, particularmente os de transmissão televisiva, passaram a ter um papel ainda mais importante na construção da opinião pública, constituindo, para grande parte da população, uma fonte de informação fiável e essencial para a compreensão da realidade circundante.

Um olhar retrospetivo rapidamente põe em evidência as mudanças abruptas e profundas impostas à sociedade pela conjuntura pandémica. Importa, então, saber de que forma essas alterações extralinguísticas influenciaram a componente lexical, particularmente a mobilizada no discurso noticioso. Neste sentido, o objetivo geral do presente trabalho é contribuir para o estudo das alterações operadas no subconjunto do léxico utilizado no discurso noticioso da sociedade portuguesa aquando da chegada e da propagação da doença Covid-19 em Portugal. Visando a consecução deste propósito, proceder-se-á a uma análise comparativa dos itens lexicais usados no mês de março de 2020, mês da chegada e da escalada da pandemia em Portugal, com o período homólogo do ano anterior: março de 2019. A análise centrar-se-á no discurso oral veiculado em várias edições de um noticiário do canal de televisão pública portuguesa.

Este trabalho prossegue com a apresentação, na secção seguinte, das linhas teóricas que enquadram o estudo, fornecendo uma visão geral das pesquisas realizadas no âmbito das frequências lexicais e da metaforização no discurso jornalístico, particularmente na abordagem a crises sanitárias. Seguidamente, são elencados os objetivos específicos da investigação e os aspetos metodológicos, entre os quais a constituição do corpus discursivo e as opções tomadas no tratamento e na análise dos dados. Na secção 4 , procede-se à descrição e à discussão dos resultados, seguindo-se a conclusão, com as considerações finais.

\section{Enquadramento teórico}

O conceito de léxico surge, na descrição teórica, frequentemente associado ao conceito de vocabulário, sendo que o primeiro remete para a globalidade das palavras que estão ao dispor do falante e o segundo para um subconjunto, composto pelos itens lexicais que um determinado indivíduo produz num contexto espácio-temporal específico. Quer um quer outro são, contudo, manifestações do léxico interiorizado na mente dos falantes (Rio-Torto 2013).

Conforme anteriormente referido, o dinamismo e a plasticidade são duas propriedades inerentes ao léxico. Este é um corpo vivo e em constante mudança, motivada também por fatores de natureza sociolinguística, política ou histórica (Ulanska, Kuzmanovska, Todorova, \& Kirova 2020). Neste sentido, o léxico pode ser perspetivado como um reflexo da visão que os falantes têm do mundo, materializada em unidades lexicais, usadas na comunicação: “O Léxico não só codifica 
a visão que os falantes têm ou fazem da realidade extralinguística e a representação que desta elaboram, como também a armazena, a processa e a utiliza comunicativamente" (Rio-Torto 2013: 8).

\subsection{O léxico nos estudos de frequências}

A investigação tem vindo a dar relevo ao papel das frequências de ocorrência das unidades linguísticas em diferentes domínios. A título exemplificativo, saliente-se a relação que tem sido identificada entre o grau de frequência das estruturas, o seu estatuto mais ou menos marcado nas línguas e a ordem de aquisição. Neste contexto, os estudos relatam que as unidades linguísticas mais frequentes tendem a apresentar um estatuto universal, não marcado e, como tal, figuram tendencialmente entre as primeiras estruturas adquiridas durante o processo de desenvolvimento linguístico. No domínio específico dos itens lexicais, alguns trabalhos têm mostrado a relevância da frequência das palavras para o processamento e para a leitura, mostrando que a previsibilidade dos itens mais frequentes acelera os processos de reconhecimento e de produção (Vigário, Frota, Martins \& Cruz 2012; Brysbaert, Mandera \& Keuleers 2018). Refira-se ainda o conjunto de estudos que relaciona os níveis de frequência das palavras com as ideologias transmitidas no discurso. Nesta linha de investigação, defende-se que as frequências lexicais podem ser indiciadoras dos padrões de representação ideológica subjacentes, refletindo as crenças e os valores partilhados por uma determinada comunidade (Vessey 2017).

A frequência com que são usadas as palavras pode, assim, influenciar o processamento, revelar ideologias e, globalmente, caracterizar as vivências físicas e emocionais de uma comunidade. Nesta perspetiva, tem surgido um interesse especial de investigação sobre o vocabulário predominante na sociedade no contexto da doença Covid-19. Os efeitos da pandemia têm sido muito grandes na vida de cada indivíduo, influindo na saúde física e emocional, nas circunstâncias profissionais e económicas, nas relações familiares e nas rotinas comunicacionais. Esse impacto generalizado na comunidade gerou uma proliferação de itens lexicais direta ou indiretamente ligados ao novo Coronavírus nas interações comunicativas, quer nas conversações pessoais quer no discurso público, difundido nas redes sociais e nos meios de comunicação em massa. O interesse neste campo tem levado à constituição de corpora específicos, estruturados sobretudo a partir das palavras veiculadas no discurso mediático. A este propósito, veja-se, para o inglês, o Coronavirus Corpus (Mark Davis 2020) e o Covid-19 Corpus (Sketch Engine 2020).

A curiosidade científica sobre o vocabulário na era Covid tem levado também à realização de estudos de frequência. Refira-se o estudo de Hajar Rahim (Tan et al. 2020), que analisa as frequências de ocorrência das expressões 'virus', 'coronavirus', 'epidemic', 'pandemic', 'new coronavírus', 'flatten the curve', 'stay at home' e 'work from home', durante um período de seis meses. O autor estabelece uma relação entre o momento em que as expressões surgem com maior frequência e as alterações ocorridas na sociedade local e mundial; assim, por exemplo, observou que a palavra 'vírus' atinge o pico em fevereiro ao passo que, em março, a expressão 'flatten the curve' se torna predominante. Este trabalho enfatiza, por conseguinte, a influência da realidade extralinguística no uso do léxico, mostrando que as frequências das palavras constituem um indicador das mudanças no foco de atenção da discussão pública. Na mesma área de pesquisa, saliente-se ainda a investigação desenvolvida por Kwan \& Lim (2020), baseada em 910,000 textos publicados na 
rede twitter. O estudo incide particularmente na variação das emoções ao longo do tempo, no período compreendido entre março e junho de 2020, assim como na relação desses sentimentos com os eventos que vão marcando o quotidiano social pandémico e que constituem os tópicos de discussão mais frequentes. Entre outros aspetos, os autores reportam, nos resultados obtidos, evidências de uma estreita relação entre os eventos em larga escala e as emoções: por exemplo, as emoções negativas tornaram-se predominantes nos tweets estudados logo após a declaração da doença como pandemia, tendo nesse período aumentado a prevalência de palavras associadas ao medo e à ansiedade.

\subsection{Os itens lexicais no discurso noticioso: sentidos implícitos}

O discurso dos meios de comunicação social apresenta-se como um ambiente privilegiado para a observação dos itens lexicais na sua relação com a sociedade, visto que nesse contexto comunicativo, particularmente no noticioso, são abordados os maiores temas da atualidade e postos em relevo os desejos e as preocupações do público que, enquanto destinatário, é interpelado e envolvido diretamente na comunicação (Rodrigues 2015).

Para além de ser indiciador dos padrões de frequência lexical na sociedade, o discurso dos média desempenha também um papel determinante enquanto instrumento de construção da realidade social e de formação da opinião pública (Teixeira \& Oliveira 2017). Essa natureza ideológica do discurso dos média tem sido analisada em vários estudos, que reportam a influência da abordagem noticiosa na sociedade: "news media discourse is pervasive, which suggests that our real-world experiences and everyday lives are influenced - to a considerable degree - by media and media language, whether as newspapers, TV and radio news bulletins, news websites etc." (Kort 2017: 75).

Nesta linha de investigação, que observa o papel ideológico do discurso dos média, surgem alguns estudos que, no quadro da Linguística Cognitiva, analisam o uso da metáfora conceptual no discurso jornalístico. As ideias defendidas nesses trabalhos são sucintamente explicitadas na secção que se segue.

\subsubsection{A teoria da Metáfora Conceptual}

A teoria da metáfora conceptual (Lakoff \& Johnson 1980; 1999) assenta no pressuposto de que o pensamento humano incorpora uma natureza metafórica. Esta permite aos indivíduos, entre outros aspetos, facilitar a compreensão, associando conceitos abstratos a realidades mais concretas e inteligíveis (Charteris-Black and Musolff 2003). Neste quadro da Linguística Cognitiva, a emergência da metáfora no discurso surge como uma consequência natural do facto de o próprio pensamento humano se processar de forma metafórica: "If we use metaphors, it is essentially because we think metaphorically" (Kort 2017: 32).

Do ponto de vista operativo, a metáfora conceptual consiste num mapeamento entre duas representações mentais ou domínios cognitivos: o domínio-fonte e o domínio-alvo (Kovecses et al. 2010; Silva 2013). No domínio-fonte está representado o conhecimento concreto, construído com 
base nas experiências e nas perceções acumuladas e é a partir dele que são geradas correspondências com os domínios conceptuais que se quer (fazer) compreender (Kort 2017).

Neste quadro teórico, as experiências sensório-motoras dos indivíduos, tais como os movimentos de subida e de descida, estão na base das conceptualizações (Johnson 1987). Esse saber empírico dá origem a esquemas imagéticos, como a orientação espacial EM CIMA - EM BAIXO, que alimenta metáforas conceptuais como MAIS É EM CIMA e MENOS É EM BAIXO. Estas metáforas globalizantes, por sua vez, corporizam-se linguisticamente em expressões metafóricas como "estar em alta" ou 'sentir-se em baixo'. Deste modo, os esquemas imagéticos, formados a partir das vivências quotidianas do indivíduo, operam como mapas pré-conceptuais, que apoiam a construção do pensamento, particularmente no que diz respeito a conceitos abstratos (Silva 2006).

Saliente-se que, nesta perspetiva teórica, as conceções de metáfora e de expressão metafórica são distintas, refletindo-se essa diferença na forma como são representadas na escrita. Assim, a metáfora, que consiste na correspondência conceptual entre domínios, é representada graficamente em maiúsculas pequenas através da fórmula X É Y - por exemplo, VÍRUS É GUERRA; essa metáfora é concretizada na expressão metafórica, que constitui a representação linguística desse mapeamento, como por exemplo em "o governo empenha-se no combate".

A investigação realizada tendo por base a teoria da metáfora conceptual tem reportado evidências da produtividade deste paradigma na análise de expressões metafóricas no discurso jornalístico (Chiang \& Duann 2007; Gonzalez et al. 2011; Silva 2013; Costa no prelo). Entre outros aspetos, os resultados destes trabalhos mostram que diferentes combinatórias e hierarquizações de metáforas conceptuais podem emergir no discurso mediático ao serviço de diferentes propósitos. Neste âmbito, a metáfora "serve para captar a atenção do leitor, para o levar a compreender o que se passa no mundo e até para lhe impor determinada forma de pensar e/ou agir." (Silva 2013: 13). A metáfora pode, portanto, ser usada no discurso noticioso com o objetivo heurístico de ajudar o leitor a compreender conceções pouco inteligíveis, mas também pode ter o propósito de criar respostas emocionais e comportamentais, mediante a criação de efeitos cognitivos diversos (Pinto \& Pereira 2014; Kort 2017).

A investigação tem tornado evidente a recorrência de determinadas metáforas no discurso jornalístico. No domínio específico dos trabalhos sobre a cobertura jornalística de crises sanitárias, entre as metáforas mais frequentes surgem aquelas assentes em domínios fonte como a guerra, a pessoa e o desastre natural. Saliente-se, neste âmbito, o trabalho de Chiang \& Duann (2007) sobre as conceptualizações metafóricas na abordagem da imprensa ao surto de Síndrome Respiratória Aguda (SARS) em 2003, em Taiwan e China, assim como a investigação desenvolvida por Gonzalez et al. (2011), que incide no uso da metáfora na abordagem da imprensa mexicana ao surto de vírus H1N1, em 2009. Os dois trabalhos reportam uma associação do vírus a elementos bélicos e a catástrofes naturais, servindo essas conceptualizações metafóricas, de acordo com os autores, diferentes funções pragmáticas e ideológicas. Costa (no prelo) estudou o uso da metáfora em quarenta edições impressas de quatro jornais portugueses, relativas ao período compreendido entre março e maio de 2020. Os seus resultados mostram a existência de quatro metáforas conceptuais particularmente produtivas no discurso analisado: VÍRUS É INIMIGO; VÍRUS É PESSOA; VÍRUS É PERTURBAÇÃO DA NATUREZA; PANDEMIA É VIAGEM, que se operacionalizam em diversas expressões metafóricas, numa rede de relações de interdependência e de hierarquia. 


\section{Objetivos e Metodologia}

Conforme explicitado anteriormente, com esta investigação pretende-se contribuir para o conhecimento existente acerca dos efeitos de fatores extralinguísticos no domínio lexical. Mais concretamente, pretende-se estudar as influências da Covid-19 no vocabulário noticioso em Portugal.

Como fonte discursiva, optou-se pelo noticiário emitido em horário nobre do canal de televisão pública portuguesa, o Telejornal da RTP. Sendo que se pretende identificar eventuais alterações provocadas pela doença no uso lexical, tornou-se necessário constituir também um referencial discursivo pré-pandemia, de forma a viabilizar um estudo comparativo. Criou-se então um corpus com dois subconjuntos discursivos extraídos de edições do Telejornal: (i) um conjunto relativo a março de 2020, mês do início e da escalada pandémica em Portugal; (ii) e outro relativo ao período homólogo do ano anterior, março de 2019.

A esta investigação subjazem os seguintes objetivos específicos: (1) Identificar os níveis de frequência lexical em março de 2019 e em março de 2020; (1.1.) Estabelecer comparações entre os resultados das frequências nos dois períodos em estudo; (2) Identificar relações entre a variação nas frequências lexicais ao longo de março de 2020 e a evolução da doença no país; (3) Analisar as expressões metafóricas usadas na abordagem à pandemia.

No que diz respeito à constituição do corpus, este é formado por 12 edições do Telejornal RTP emitidas ao longo do mês de março de 2019 e por 17 edições do mesmo noticiário, emitidas em março de 2020. Procedeu-se, em primeiro lugar, à transcrição do conteúdo oral das diferentes sessões para texto escrito, tendo este procedimento sido realizado em duas fases. Inicialmente, cada edição, disponível em linha no endereço eletrónico do respetivo canal televisivo, foi integralmente submetida à aplicação Chrome VoiceNote - Speech Recognition Platform, para conversão automática para a escrita. Posteriormente, os ficheiros foram revistos pela investigadora, de forma a corrigir as imprecisões inerentes à conversão automática e a suprimir os excertos textuais ininteligíveis. Saliente-se que foi feita a transcrição de toda a edição, incluindo não só o discurso do jornalista pivô, mas também dos repórteres, dos convidados em estúdio e dos entrevistados no exterior. Procurou-se, dessa forma, reconstituir um cenário o mais aproximado possível da globalidade da exposição lexical a que os telespetadores do programa estiveram sujeitos durante cada emissão.

Os dados foram depois analisados com recurso ao software NVivo 13, que permitiu, entre outros aspetos, identificar os níveis de frequências de palavras e observar os respetivos contextos de ocorrência. Por opção metodológica, a análise incidiu em itens lexicais nominais, adjetivais e verbais. No caso dos nomes e dos adjetivos, a análise de frequência foi feita por palavra; no entanto, para os verbos, dada a grande quantidade de formas possíveis e verificadas no corpus, optou-se, na linha de estudos lexicais como o de Soares et al. (2014), por agregar as formas flexionadas por lema, neste caso, pelo infinitivo. Deste modo, os valores de ocorrência de, por exemplo, 'ser' incluem o número de produções de todas as formas flexionadas deste verbo, tais como 'são, 'e’' ou 'serão'. Globalmente, foram analisadas 43940 palavras (nomes, verbos e adjetivos), das quais 16185 integram o subcorpus de 2019 e 27755 o subcorpus de 2020.

A análise apresentada será de natureza quantitativa e qualitativa, no sentido em que se irá aliar a identificação de valores de frequência à exploração do contexto em que as palavras são utilizadas, aos sentidos que adquirem e às possíveis intenções comunicativas subjacentes. 


\section{Descrição e discussão dos dados}

Nesta secção, serão apresentados e discutidos os principais resultados obtidos, em duas grandes partes. Em primeiro lugar, abordar-se-á a frequência de ocorrência dos itens lexicais, nos dois subconjuntos temporais analisados, março de 2019 e março de 2020. Essa abordagem subdivide-se pelas classes dos nomes e adjetivos (secção 4.1.1) e pela classe dos verbos (secção 4.1.2). Posteriormente, na secção 4.2., a ênfase será colocada na análise da relação entre os itens lexicais e a metáfora, no subcorpus de março de 2020.

\subsection{Frequências de ocorrência}

Em seguida, faz-se a descrição e a comparação dos valores de ocorrência dos nomes, adjetivos e verbos nos dois períodos temporais em análise.

\subsubsection{Nomes e Adjetivos}

A título introdutório, apresenta-se, na Figura 1, as nuvens de frequência dos nomes e dos adjetivos em cada subcorpus, extraídas a partir do NVivo. Repare-se que, neste tipo de representação gráfica, o nível de frequência é diretamente proporcional ao tamanho da letra e à sua centralidade: as palavras mais frequentes surgem destacadas, em tamanho maior, no centro da nuvem.

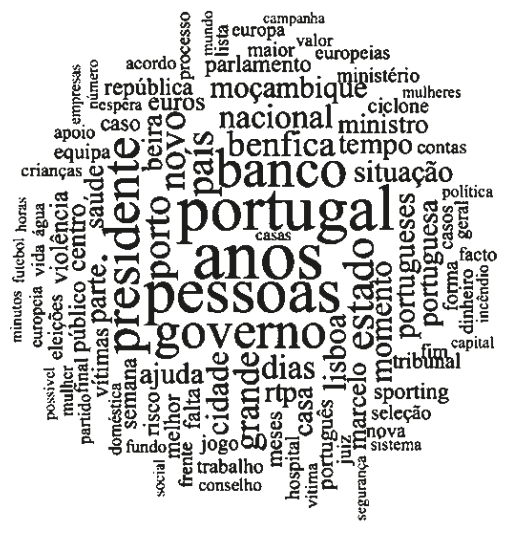

Março de 2019

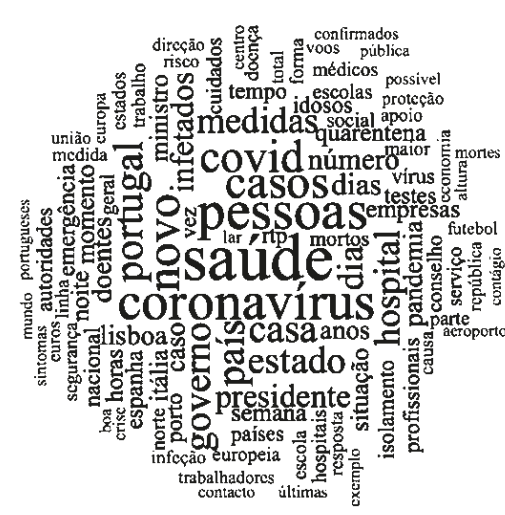

Março de 2020

Figura 1: Frequências de nomes e adjetivos: março de 2019 vs março de 2020

As nuvens lexicais acima apresentadas evidenciam um contraste entre os dois grupos de dados. Em 2019, as formas nominais e adjetivais mais frequentes, entre as quais os vocábulos 'governo, 'banco, 'Benfica' e 'Moçambique’ ou 'Porto', distribuem-se por áreas temáticas diversificadas, que incluem 
a política, a economia, o futebol e as consequências do ciclone Idai em Moçambique. Em contraste, no período homólogo de 2020, verifica-se um afunilamento das palavras mais frequentes, em torno de um tema comum: a pandemia passou a dominar o discurso noticioso, com prevalência de nomes e adjetivos como 'saúde,' 'Coronavírus', 'novo, 'Covid', 'casos', 'casa' ou 'infetados'.

Em seguida, formula-se uma análise mais detalhada dos níveis de ocorrência. Por razões que se prendem com a limitação de extensão deste trabalho e na linha de outros estudos dedicados à frequência de palavras (Nascimento \& Isquerdo 2003; Muhammad, Zhiyong, Iram \& Nisar 2020) optou-se por circunscrever a apresentação aos 20 itens lexicais mais frequentes, num e noutro período temporal. Em seguida, na Tabela 1, apresenta-se uma hierarquização comparativa desses dados.

Tabela 1: Top 20 de frequência para nomes e adjetivos: março de 2019 vs março de 2020

\begin{tabular}{|c|c|c|c|c|c|}
\hline março de 2019 & $\mathrm{n}$ & $\%$ & março de 2020 & $\mathrm{n}$ & $\%$ \\
\hline anos & 139 & $9 \%$ & saúde & 363 & $9 \%$ \\
\hline Portugal & 125 & $8 \%$ & pessoas & 293 & $8 \%$ \\
\hline pessoas & 123 & $8 \%$ & Coronavírus & 289 & $7 \%$ \\
\hline banco & 104 & $7 \%$ & novo & 248 & $6 \%$ \\
\hline presidente & 100 & $6 \%$ & casos & 245 & $6 \%$ \\
\hline governo & 99 & $6 \%$ & Covid-19 & 239 & $6 \%$ \\
\hline estado & 82 & $5 \%$ & Portugal & 211 & $5 \%$ \\
\hline país & 76 & $5 \%$ & país & 201 & $5 \%$ \\
\hline Porto & 74 & $5 \%$ & casa & 198 & $5 \%$ \\
\hline novo & 73 & $4 \%$ & governo & 189 & $5 \%$ \\
\hline Benfica & 67 & $4 \%$ & estado & 181 & $5 \%$ \\
\hline grande & 67 & $4 \%$ & hospital & 172 & $5 \%$ \\
\hline nacional & 62 & $4 \%$ & medidas & 171 & $4 \%$ \\
\hline dias & 61 & $4 \%$ & dia & 169 & $4 \%$ \\
\hline cidade & 58 & $4 \%$ & infetados & 150 & $4 \%$ \\
\hline Lisboa & 57 & $4 \%$ & presidente & 145 & $4 \%$ \\
\hline momento & 57 & $4 \%$ & número & 132 & $3 \%$ \\
\hline Moçambique & 55 & $3 \%$ & Lisboa & 117 & $3 \%$ \\
\hline portugueses & 55 & $3 \%$ & doentes & 115 & $3 \%$ \\
\hline situação & 55 & $3 \%$ & pandemia & 109 & $3 \%$ \\
\hline Total & 1589 & $100 \%$ & Total & 3937 & $100 \%$ \\
\hline
\end{tabular}

Importa salientar que nove das vinte palavras (45\%) são comuns aos dois conjuntos de dados: 'pessoas'; 'novo'; 'Portugal'; 'país; ' 'governo'; 'estado'; 'dia(s)'; 'presidente’; 'Lisboa. Os restantes 11 vocábulos em que 2020 difere de 2019 estão diretamente relacionados com a temática da pandemia: 'saúde’; 'Coronavírus'; 'casos'; 'Covid-19'; 'casa'; 'hospital'; 'medidas'; 'infetados'; 'número'; 'doentes'; 'pandemia'. As semelhanças e diferenças lexicais no top 20 de ambos os grupos surgem em seguida. 


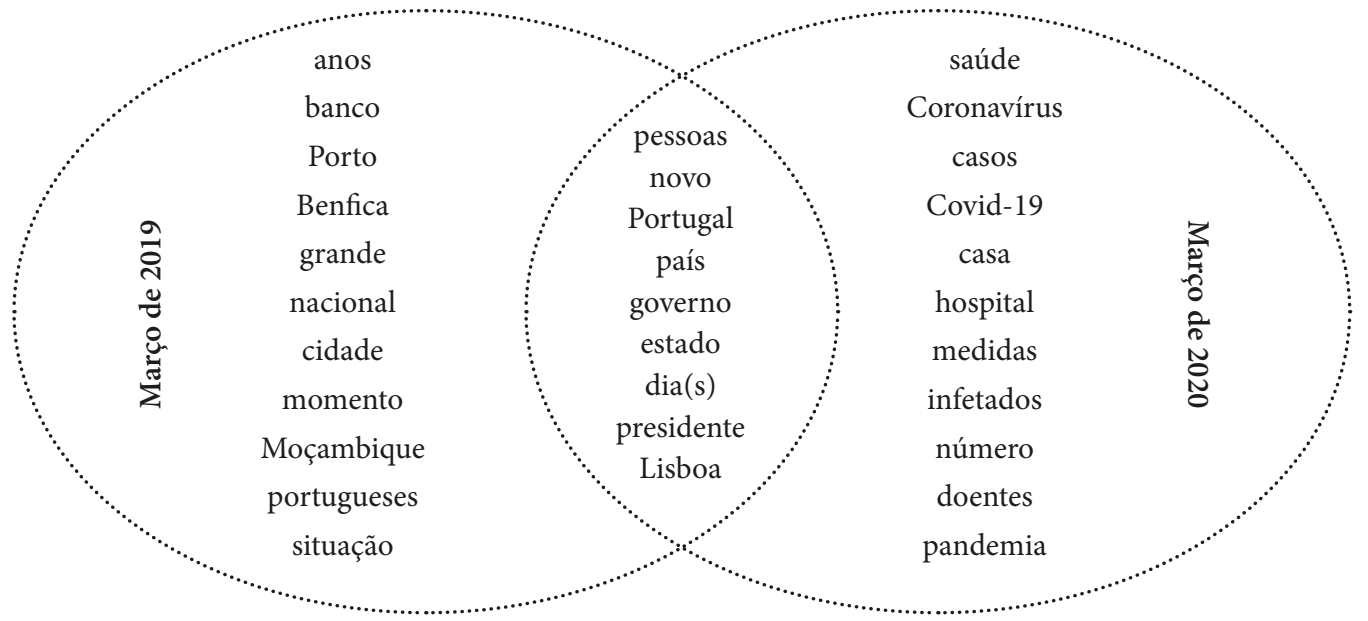

Figura 2: Nomes e adjetivos predominantes em março de 2019 e de 2020: semelhanças e diferenças

Focando a atenção nas dissemelhanças entre os dois grupos, constata-se que a pluralidade temática verificada em 2019, com a predominância de vocábulos alusivos à política, ao desporto ou à economia, deu lugar a uma tendência para a centralidade em 2020, visto que mais de metade dos nomes e adjetivos que compõem o respetivo top 20 de frequência está relacionada com a pandemia.

Verifica-se ainda que existem palavras no subcorpus de 2020 que não constam do subcorpus de 2019, tais como 'confinamento'; 'pandemia'; 'quarentena'; 'lar(es)'; 'máscara(s)'; 'videoconferência'. Apesar não serem neologismos, estes vocábulos passaram a ter uma relevância especial no discurso noticioso em contexto pandémico.

Adicionalmente, há palavras que, apesar de constarem dos dois grupos de dados, tornaramse mais frequentes em 2020. Exemplo desta situação é o vocábulo 'casa' que, em 2020, surge em nono lugar do top 20 da hierarquia de frequências de nomes e adjetivos e, em 2019, surge na 27. posição. Este relevo dado à palavra 'casa' decorre das mudanças ocorridas na sociedade: ficar em casa passou a ser fortemente recomendado como medida preventiva da doença e, com a imposição do confinamento geral obrigatório, a casa de cada cidadão passou a ter um papel central. Em seguida, são apresentados alguns contextos em que, no corpus analisado, a palavra 'casa' emerge no discurso noticioso (ver Figura 3).

Verifica-se que muitas das ocorrências dizem respeito à expressão muito difundida 'ficar em casa', associada a palavras como 'isolamento', 'monitorização', 'evitar' (o contacto social) e 'travar' (o contágio). A frequência de ocorrência da expressão 'ficar em casa' resulta da necessidade de incutir essa recomendação na consciência coletiva dos telespetadores, numa altura em que, sem vacina à vista, a prevenção é a forma mais efetiva de combate à pandemia.

Os dados permitem ainda verificar relações entre os níveis de frequência e a linha cronológica dos acontecimentos sociais. Veja-se, em primeiro lugar, o caso dos vocábulos 'Coronavírus' e 'Covid-19'. Repare-se que, no sexto lugar da hierarquia de frequência de março de 2020, com 239 ocorrências (ver Tabela 1), surge o neologismo 'Covid-19'. Nos dados totais, este emerge com 


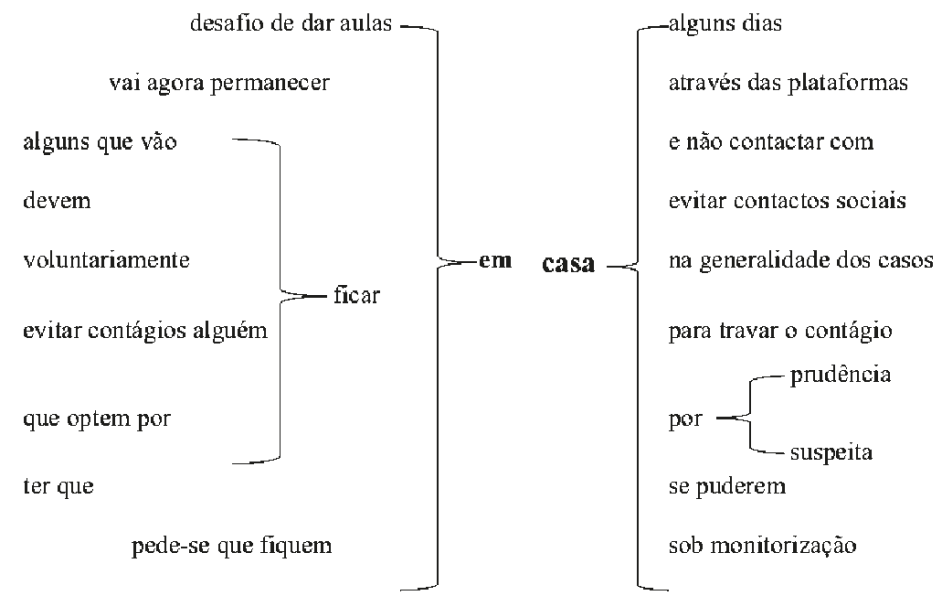

Figura 3: Contextos predominantes de ocorrência do nome 'casa' no corpus de 2020

As palavras Coronavírus e Covid-(19): número de ocorrências numa perspetiva longitudinal

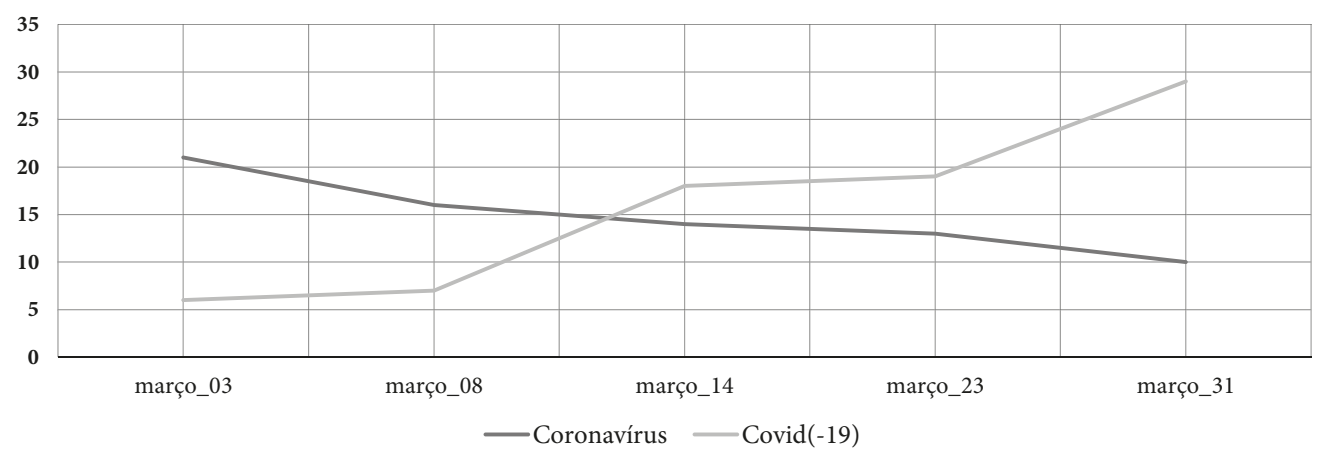

Figura 4: Frequência das palavras 'Coronavírus' e ‘Covid-19', ao longo do mês de março de 2020

menor frequência do que o termo 'Coronavírus', que constitui uma denominação meronímica do neologismo, no sentido em que o acrónimo Covid-19 é o nome da doença e Coronavírus é o agente viral que a causa (Haddad \& Montero-Martínez 2020). No entanto, se analisarmos a ocorrência destes dois vocábulos ao longo do mês, verificamos que há mudanças, conforme patente no gráfico que se segue (ver Figura 4).

O gráfico mostra que o neologismo criado pela OMS vai ganhando predominância sobre o nome do vírus, ao longo do tempo, à medida que esse acrónimo se vai tornando mais familiar na sociedade.

Efeitos similares da passagem do tempo nos níveis de frequência ficam evidentes nos vocábulos 'morte, 'casa,' 'casos', 'idoso(s)' e 'infetado(s)', conforme gráfico que se segue.

O gráfico mostra uma tendência crescente a partir da sessão de 14 de março para as palavras 'idoso(s)' e 'morte(s)', ao passo que os termos 'infetado(s)', 'casa' e 'casos' iniciam mais cedo o seu 
Léxico associado à pandemia: número de ocorrências numa perspetiva longitudinal

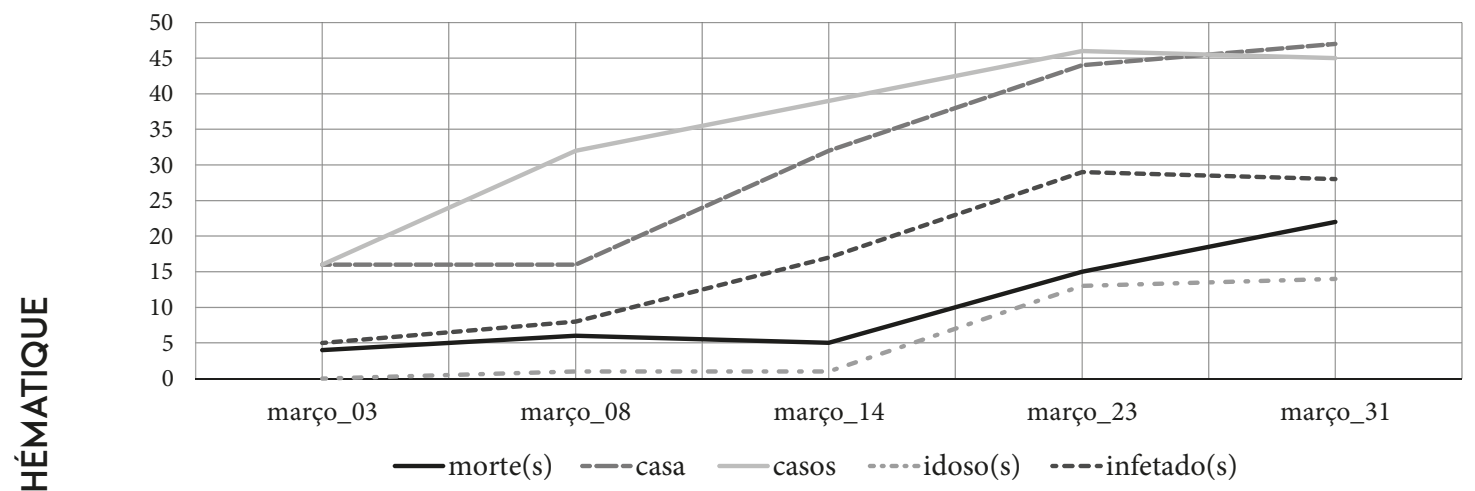

Figura 5: Alterações nas frequências lexicais, ao longo do mês de março de 2020

período ascendente de frequência de ocorrência, já desde a sessão do dia 08 de março. Estes valores podem ser interpretados como um reflexo dos eventos e das preocupações que ocorreram na sociedade portuguesa durante esse período. No início do mês, com poucos doentes, a preocupação maior consistia em isolar os casos suspeitos em casa e observar o número de infeções. No entanto, cerca de uma semana depois, Portugal já contabilizava mais de três centenas de infetados e uma morte. A preocupação era então cada vez maior com o índice de mortalidade da doença e com a necessidade de proteção das pessoas mais vulneráveis, os idosos. O discurso noticioso reflete, assim, não só as preocupações sociais, mas a variação no grau de intensidade das mesmas, ao longo do tempo.

\subsubsection{Verbos}

Tal como explicitado na secção da metodologia, na análise das frequências das formas verbais optou-se por agrupar os dados por lema; assim, por exemplo, formas verbais como 'estou', 'estive' e 'estivemos' surgem, na tabela abaixo, agrupadas no verbo 'estar'.

A Tabela 2 permite a comparação entre os vinte verbos mais frequentes em cada período temporal estudado.

Tabela 2: Os vinte verbos mais frequentes: março de 2019 vs março de 2020

\begin{tabular}{|l|c|c|l|c|c|}
\hline \multicolumn{1}{|c|}{ março de 2019 } & n & \% & março de 2020 & n & \% \\
\hline ser & 731 & $24 \%$ & ser & 1562 & $30 \%$ \\
\hline ter & 498 & $16 \%$ & estar & 1017 & $19 \%$ \\
\hline estar & 438 & $14 \%$ & ter & 838 & $16 \%$ \\
\hline ir & 298 & $10 \%$ & poder & 307 & $6 \%$ \\
\hline
\end{tabular}




\begin{tabular}{|l|c|c|l|c|c|}
\hline \multicolumn{1}{|c|}{ março de 2019 } & n & \% & \multicolumn{1}{c|}{ março de 2020 } & n & $\%$ \\
\hline fazer & 163 & $5 \%$ & fazer & 217 & $4 \%$ \\
\hline poder & 190 & $6 \%$ & ficar & 180 & $3 \%$ \\
\hline dizer & 146 & $5 \%$ & dizer & 165 & $3 \%$ \\
\hline ficar & 90 & $3 \%$ & chegar & 106 & $2 \%$ \\
\hline chegar & 76 & $3 \%$ & saber & 90 & $2 \%$ \\
\hline pedir & 48 & $2 \%$ & começar & 89 & $2 \%$ \\
\hline ver & 30 & $1 \%$ & partir & 86 & $2 \%$ \\
\hline dar & 35 & $1 \%$ & haver & 82 & $2 \%$ \\
\hline começar & 46 & $2 \%$ & dever & 70 & $2 \%$ \\
\hline falar & 23 & $1 \%$ & continuar & 74 & $1 \%$ \\
\hline precisar & 44 & $1 \%$ & passar & 71 & $1 \%$ \\
\hline saber & 39 & $1 \%$ & morrer & 60 & $1 \%$ \\
\hline continuar & 50 & $2 \%$ & dar & 54 & $1 \%$ \\
\hline acontecer & 38 & $1 \%$ & trabalhar & 54 & $1 \%$ \\
\hline ajudar & 21 & $1 \%$ & ver & 5257 & $100 \%$ \\
\hline ganhar & 21 & $1 \%$ & precisar & & \\
\hline Total & 3025 & $\mathbf{1 0 0} \%$ & Total & & 78 \\
\hline
\end{tabular}

Verifica-se que a maioria dos verbos mais frequentes (14 dos 20) é comum aos dois conjuntos de dados. Muitos destes verbos partilhados pelos dois subcorpora são auxiliares e modais e a sua elevada frequência tem sido atestada em várias línguas, incluindo no Português (Nascimento \& Isquerdo 2003). Importa para este estudo focar sobretudo os verbos que não são comuns aos dos conjuntos, listados nos extremos do diagrama apresentado na Figura 6.

Do conjunto de verbos mais frequentes em 2020 e que diferem de 2019, destaque-se os verbos 'dever,' 'morrer' e 'trabalhar'. No corpus, estes surgem predominantemente associados à pandemia, conforme exemplos em seguida.

As formas do verbo 'dever' surgem em três contextos principais, associados à doença. Por um lado, o verbo emerge na prescrição de comportamentos e atitudes, veiculando principalmente um valor modal de obrigação ou de proibição: "se estiver infetado deve ficar em casa"; o "serviço deve ter um plano de contingência"; "não se deve entrar em alarmismos"; ou "não devem estar juntos na mesma divisão". Adicionalmente, num tempo de incertezas, que leva a tecer conjeturas e hipóteses, surgem várias utilizações com valor modal de probabilidade e de possibilidade: "a vacina para o novo Coronavírus deve demorar ainda um ano"; "nesta corrida, a vacina só deverá estar disponível dentro de um ano" ou "medidas aprovadas pelo governo amanhã e deve constar nessas medidas a proibição de”.

Quanto às formas do verbo 'trabalhar', estas tornam-se particularmente frequentes em expressões associadas ao teletrabalho, como "trabalhar a partir de casa". Surgem também em denúncias à falta de condições, que determinam a "impossibilidade de trabalhar" ou que afetam o pessoal de saúde "a trabalhar sem equipamento de proteção individual". Emergem ainda em recomendações 


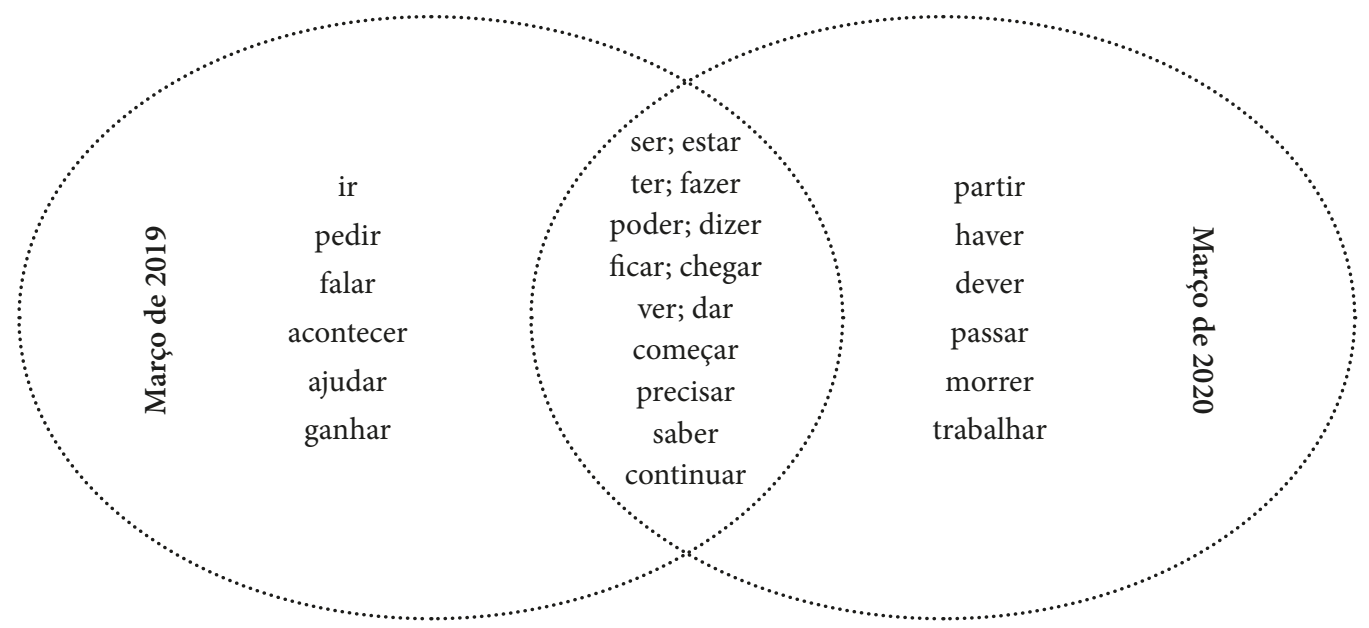

Figura 6: Verbos predominantes em março de 2019 e de 2020: semelhanças e diferenças

e alertas, pois é importante "abster-se de ir trabalhar" em situações suspeitas de doença. Outro contexto de utilização é o da atuação de entidades governativas, empresariais e cidadãos anónimos, todos a "trabalhar intensivamente na luta contra o Covid".

Por fim, as formas do verbo 'morrer' surgem associadas a duas principais vítimas da doença Covid-19: as pessoas e a economia. Em relação aos seres humanos, faz-se um relatório diário minucioso do número de mortes em Portugal e em todo o mundo: “em Itália já morreram”, com foco nos mais velhos: "idosos que estão a morrer todos os dias". Quanto à economia, ocorrem expressões que refletem a preocupação crescente com o impacto da doença: "as economias não podem morrer" e "se, entretanto, a economia não morrer".

Em síntese, este estudo comparativo mostra, numa microescala, uma visão da forma como o uso do léxico é permeável à realidade social circundante. Entre março de 2019 e março de 2020, o foco da atenção e da discussão social mudou e, como tal, o vocabulário mudou também. Há palavras que ganham um maior destaque na sociedade com a chegada e desenvolvimento da pandemia. Acresce que essa mudança não é visível apenas na comparação entre 2019 e 2020. É possível ver também a influência extralinguística no decorrer do mês de março de 2020, no estudo longitudinal de algumas palavras. $\mathrm{O}$ aumento de frequência desses itens lexicais sobretudo a partir da segunda semana de março reflete as mudanças e a escalada pandémica. Estes resultados vão ao encontro das observações de Kwan \& Lim (2020), relativamente à influência dos fenómenos pandémicos nas palavras e nas emoções que representam, assim como corroboram os resultados referidos em Tan et al. (2020), que enfatizam a influência da realidade extralinguística no uso do léxico, mostrando que as frequências lexicais constituem um indicador das mudanças no foco de atenção da discussão pública, em contexto Covid. 


\subsection{Metáforas usadas na abordagem à pandemia}

A análise do subcorpus de março de 2020 permitiu identificar um conjunto de palavras que, apesar de não serem novas no léxico, assumem um novo sentido, de natureza metafórica, na abordagem noticiosa à pandemia. Globalmente, esses itens lexicais podem ser integrados em dois grandes domínios cognitivos: o da guerra e o da perturbação da natureza.

Começando pelo tema bélico, no discurso noticioso analisado alude-se a uma "guerra contra um inimigo invisível”, uma "luta desigual", em que os hospitais são "quartéis da batalha" e os profissionais de saúde estão "na linha da frente" ou "na frente de batalha”. Neste enredo, todos os cidadãos são chamados a cumprir o seu papel, pois "temos de ser todos soldados". A "ameaça do novo vírus" põe em risco a sobrevivência, o que leva a OMS a pedir "uma operação de ataque", sendo necessário verificar "o que está a falhar no combate". As medidas "inéditas", "excecionais" e "drásticas" a implementar no combate ao vírus inimigo têm de ser "apertadas", "musculadas" e “duras". Nas áreas mais afetadas, como Itália ou Espanha, vive-se um "cenário de guerra”, um "cenário de horror". Estas expressões metafóricas constituem corporizações linguísticas da metáfora aglutinadora VÍRUS É INIMIGO, que se manifesta em sub-padrões metafóricos interdependentes, como COMBATE AO VÍRUS É GUERRA, COMBATER É TOMAR MEDIDAS e CUMPRIR MEDIDAS É SER SOLDADO.

A metáfora VÍRUS É INIMIGO encontra raízes na conceptualização VÍRUS É ENTIDADE, um ser inteligente, ameaçador e perigoso, que avança sobre a sociedade a um ritmo acelerado. Constituem exemplos deste modelo cognitivo as expressões que aludem à "atividade de um vírus que é extremamente inteligente" e à importância de conseguir perceber "como vai ser o comportamento do vírus". Acresce que o ritmo a que se move essa entidade inimiga é acelerado, tornando a monitorização do seu paradeiro cada vez mais difícil: "o vírus chegou a Lisboa"; "o vírus chegou ao Alentejo"; "o vírus já chegou à economia"; "autoridades sabem agora que o vírus circula no país". Importa, assim, travar o "nível de contágio galopante”, é preciso "parar o vírus”, mesmo que para isso seja necessário colocar "Portugal a meio gás”. Neste contexto, os verbos 'travar', 'conter', 'suspender' e 'adiar' surgem de forma recorrente. O objetivo é o de conter a velocidade de propagação do vírus, de forma a garantir que o SNS consiga acudir às necessidades, sem aplicar a "medicina de guerra", já em uso noutros países.

Em suma, as metáforas acima explicitadas constituem um modelo cognitivo bélico e distribuem-se numa rede de hierarquias e interdependências, representada no esquema que segue (ver Figura 7).

Assim, o modelo da guerra assenta na conceptualização do vírus como uma entidade inimiga que é necessário combater. As armas utilizadas nessa batalha são as medidas e os soldados são todos os cidadãos, com particular destaque para aqueles que estão na linha da frente, cuidando dos doentes. Na impossibilidade de erradicar o vírus, o cumprimento escrupuloso das medidas de distanciamento social viabilizará a vitória possível nesta luta: o desacelerar do avanço do vírus. Neste último aspeto, repare-se na mobilização das experiências sensório-motoras dos indivíduos, nomeadamente a dos movimentos de avanço e de paragem. Esse conhecimento empírico origina esquemas imagéticos que são recuperados nestas conceptualizações metafóricas e que apoiam a construção do pensamento e a compreensão do domínio-alvo: o isolamento social tem por principal objetivo travar essa força inimiga. 


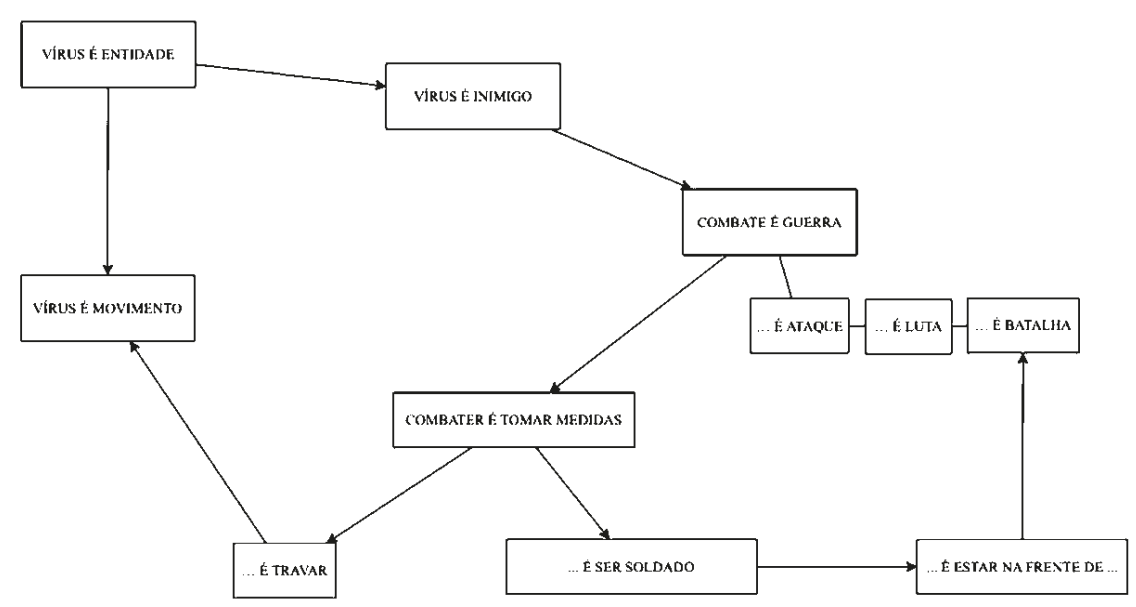

Figura 7: O Vírus num modelo cognitivo bélico: rede de conceptualizações metafóricas

O segundo grande modelo cognitivo identificado nos dados é o da pandemia como desastre natural, com consequências devastadoras na sociedade. Neste âmbito, a pandemia é conceptualizada, por exemplo, como um sismo, que tem como epicentro as zonas mais afetadas internacionalmente, com maior número de mortos e com os serviços de saúde à beira do colapso: "infeções também dispararam com o epicentro na Lombardia". O discurso noticioso veicula a constatação de que tem ocorrido "um verdadeiro tsunami de infetados" em vários países, com o aumento exponencial de doentes a necessitar de internamento, configurando uma "situação de desastre". Alerta-se, assim, para a necessidade de Portugal começar "a preparar-se para a tempestade", particularmente o SNS. Os efeitos da pandemia na economia também são descritos com base em metáforas atmosféricas e cataclísmicas, em corporizações linguísticas como "os efeitos colaterais para os empresários portugueses têm sido devastadores" ou "o governo tenta contrariar o cenário negro". Assim, a metáfora aglutinadora PANDEMIA É PERTURBAÇÃO DA NATUREZA subdivide-se em conceptualizações como PANDEMIA É SISMO, ou AGRAVAMENTO PANDÉMICO É TSUNAMI ou TEMPESTADE. Este modelo cognitivo é sistematizado na Figura 8.

O recurso aos modelos cognitivos da guerra e do desastre natural para abordar a pandemia Covid-19 foi também identificado no discurso noticioso português em jornais impressos correspondentes ao período entre março e maio de 2020, no estudo de Costa (no prelo). Esses modelos conceptuais têm também sido reportados nos últimos anos noutras investigações sobre o discurso mediático e a sua abordagem a contextos de crise económica (Silva 2013) e sanitária (Chiang \& Duann 2007; Gonzalez et al. 2011).

Globalmente, a recorrência de conceptualizações metafóricas no discurso mediático tem sido atestada na literatura da área, o que pode ser perspetivado como resultado de um dos pressupostos básicos da teoria da metáfora conceptual, no quadro da Linguística Cognitiva (Lakoff \& 


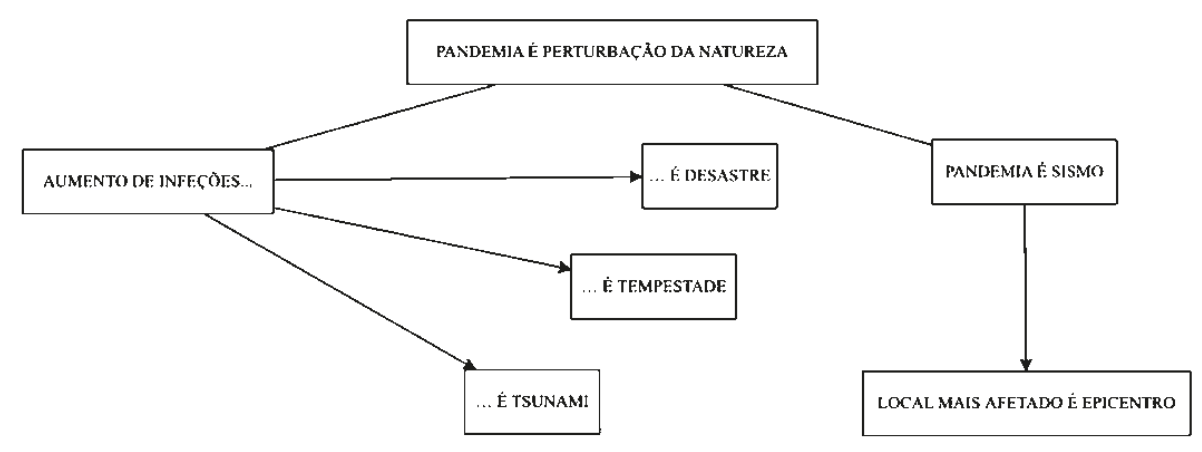

Figura 8: Modelo cognitivo cataclísmico: rede de conceptualizações metafóricas

Johnson 1980; 1999): o pensamento humano é intrinsecamente metafórico e, como tal, é natural que as expressões linguísticas emergentes na comunicação reflitam esses padrões cognitivos (Kort 2017).

Para além de poder constituir uma consequência natural do processamento cognitivo, a metaforização serve diferentes propósitos no discurso. Por um lado, destaca-se o seu pendor explicativo, um elemento fundamental para a função informativa da comunicação social. Neste âmbito, a utilização de metáforas conceptuais permite ao discurso noticioso aproximar domínios-alvo abstratos, como a ameaça pandémica, de realidades concretas e inteligíveis para o cidadão: é um inimigo, é um desastre, estamos em guerra, é preciso travar o adversário. Estas realidades tangíveis fazem, direta ou indiretamente, parte das experiências individuais e coletivas dos telespetadores e ajudarão a tornar mais inteligível o saber abstrato que se quer veicular. Os resultados aqui apresentados corroboram, desta forma, os estudos que salientam o uso de conceptualizações metafóricas com objetivos heurísticos, de explicação do ininteligível através da corporização e do experiencialismo (Charteris-Black and Musolff 2003; Silva 2006, 2013; Kovecses et al. 2010). Por outro lado, o recurso às metáforas conceptuais pode também permitir ao discurso noticioso criar no público respostas emocionais e comportamentais, incutindo perspetivas sobre formas de pensar e de agir, relativamente à pandemia. Assim, os modelos cognitivos bélico e cataclísmico podem suscitar o medo na população, levando a que respeitem as regras impostas, nomeadamente as de distanciamento social. Podem, ainda, fomentar a mobilização dos cidadãos para uma atuação coletiva contra um inimigo comum. Deste modo, os dados aqui apresentados vão ao encontro da investigação que releva a natureza ideológica subjacente às metaforizações no discurso mediático e o seu papel na construção do pensamento e da opinião do público (Chiang \& Duann 2007; Gonzalez et al. 2011; Silva 2013; Pinto \& Pereira 2014; Teixeira \& Oliveira 2017; Kort 2017). 


\section{Conclusão}

Os meios de comunicação social constituem um ambiente privilegiado para a análise da interação entre a sociedade, com as suas vivências, preocupações e anseios, e a componente lexical. Com base neste pressuposto, este trabalho incidiu no estudo de 29 edições do Telejornal do canal público RTP, sendo o corpus discursivo subdividido em dois grupos de dados: um relativo ao mês de março de 2019, ilustrativo de um período pré-pandemia, e outro relativo ao período homólogo de 2020, correspondente ao início da escalada pandémica em Portugal. Os objetivos específicos traçados visaram: (i) a identificação e a comparação das frequências lexicais nos dois períodos; (ii) a análise das palavras mais frequentes no subcorpus de 2020 e a relação das mesmas com a evolução da doença no contexto nacional e (iii) a observação dos sentidos metafóricos atribuídos às palavras, na abordagem noticiosa da pandemia.

No que diz respeito a frequência de palavras nos dois períodos estudados, os resultados mostraram uma maior diversidade temática associada aos vocábulos utilizados nas edições do noticiário de março de 2019, por oposição aos dados de 2020, em que mais de metade dos 20 itens lexicais predominantes está relacionada com a pandemia. Foram ainda identificadas palavras que não surgem nos dados de 2019 e que passam a ocorrer no ano seguinte: o neologismo Covid-19 e vocábulos como 'quarentena' ou 'pandemia', que não sendo palavras novas na língua, passam a destacar-se no vocabulário noticioso. Verificou-se ainda que existem palavras, como o nome 'casa' e os verbos 'dever' e 'trabalhar' que, apesar de surgirem também em março de 2019, ganham maior evidência em 2020, particularmente em contextos semânticos atinentes ao dever do cumprimento de regras e à necessidade de teletrabalho. Assim, globalmente, os resultados desta análise comparativa de frequências lexicais permitem encontrar evidências a favor de um valor documental do léxico (Tan et al. 2020), da sua capacidade de espelhar o modus vivendi dos indivíduos, de evidenciar os principais focos de atenção e de interesse de uma comunidade num contexto sincrónico específico, neste caso, o da pandemia.

Adicionalmente, verificou-se que as frequências do vocabulário noticioso refletem não só as preocupações sociais do ponto de vista sincrónico, mas também a variação no grau de intensidade dessas inquietações ao longo do tempo, indo ao encontro dos resultados de estudos como os de Kwan \& Lim 2020, referidos na secção 2 do presente trabalho. Esta constatação adveio do estudo longitudinal de frequências de alguns vocábulos no subcorpus de 2020, que mostrou uma estreita relação entre a evolução dos acontecimentos sociais e o crescimento da frequência de uso de determinadas palavras. Esse padrão foi evidente, por exemplo, no aumento da ocorrência discursiva dos itens 'morte' e 'idoso(s)' a partir de meados do mês de março, coincidindo socialmente com o agravamento do número de vítimas mortais, particularmente idosas. Desta forma, a linha ascendente na frequência lexical acompanha, e reflete, a focalização da atenção dos média e dos cidadãos na fatalidade da doença e na necessidade de proteção das faixas etárias mais afetadas pelo vírus.

Paralelamente ao estudo de frequências, este trabalho procurou investigar as expressões metafóricas usadas na abordagem à pandemia, no discurso noticioso de março de 2020. Numa análise baseada no quadro teórico da Metáfora Conceptual, (Lakoff \& Johnson 1980; 1999), os resultados mostraram a ocorrência de três modelos cognitivos principais: VÍRUS É ENTIDADE; VÍRUS É INIMIGO e PANDEMIA É PERTURBAÇÃO DA NATUREZA. Estas conceptualizações metafó- 
ricas dão origem a outras, que com elas se interligam, nomeadamente as metáforas COMBATER VÍRUS É GUERRA ou PANDEMIA É SISMO. Para além de serem representativas de uma experiência social coletiva, estas metaforizações podem servir diferentes propósitos comunicacionais. Desde logo, cumprem o objetivo heurístico de guiar o telespetador na compreensão de conceitos abstratos, decorrentes de uma ameaça desconhecida, por parte de um vírus invisível. A associação dessa realidade de difícil explicação a experiências diretas ou indiretas dos cidadãos, nomeadamente a de se estar a viver uma guerra, coadjuvada pela associação a experiências sensório-motoras como os movimentos de avanço e de paragem, torna mais inteligíveis as noções de perigo e de formas de combate. Desta forma, estas expressões metafóricas favorecem a compreensão da gravidade da ameaça e da importância de medidas como o isolamento social. Assim, os processos de metaforização podem, também, contribuir para a indução de comportamentos individuais ou coletivos, nomeadamente os de cumprimento das medidas de contenção da propagação do vírus. Corrobora-se, desta maneira, o papel multifacetado da metáfora conceptual que, corporizada em expressões linguísticas figuradas, é geradora de efeitos cognitivos muito diversificados (Silva 2013; Pinto \& Pereira 2014; Kort 2017).

A pandemia causou, deste modo, um forte impacto no vocabulário noticioso utilizado em março de 2020, trazendo alterações (i) nas frequências de utilização de alguns vocábulos, em detrimento de outros; (ii) nos sentidos figurados atribuídos a alguns itens lexicais, permitindo concretizar conceitos abstratos e incutir padrões de comportamento individual e social.

Em suma, o estudo aqui apresentado evidenciou, a partir de dados empíricos, a permeabilidade e a plasticidade do léxico relativamente às circunstâncias sociais envolventes. Neste caso concreto, constatou-se a influência exercida pela pandemia Covid-19 na comunicação noticiosa televisiva, sendo esse impacto refletido quer nas mudanças do grau de frequência dos itens lexicais quer nos sentidos figurados emergentes no período observado. Verificou-se que a frequência de uso das palavras e os diferentes matizes de sentido que lhes são atribuídos podem não só espelhar as vivências físicas e emocionais de uma comunidade, mas também viabilizar a transmissão de formas de pensamento e de mobilização para a ação.

Por fim, saliente-se que o subconjunto do léxico aqui estudado constitui um testemunho, em escala reduzida, das principais preocupações da sociedade portuguesa em março de 2020, tendose mostrado bastante produtivo para a análise da influência da pandemia no uso do vocabulário noticioso. Perspetivando investigação futura, seria relevante proceder ao alargamento do período estudado de forma a abranger as consecutivas vagas da pandemia em Portugal, analisando a forma como as sucessivas alterações extralinguísticas se repercutiram nas frequências lexicais e nas conceptualizações metafóricas utilizadas. Crê-se que o estudo aqui apresentado poderá ter dado o impulso necessário para a continuação desse caminho de investigação, rumo a um conhecimento cada vez mais aprofundado e diversificado das relações dialógicas mais abrangentes estabelecidas entre o léxico e a sociedade. 


\section{Referências bibliográficas}

Antunes, M. (2012). Neologia de imprensa do português. Dissertação de Doutoramento: Faculdade de Letras da Universidade de Lisboa.

Brysbaert, M.; Mandera, P.; \& Keuleers, E. (2018). The word frequency effect in word processing: an updated review. Current Directions in Physchological Science, 27, 45-50.

Charteris-Black, J.; \& Musolff, A. (2003). "Battered hero" or "innocent victim"? A comparative study of metaphors for euro trading in British and German financial reporting. English for Specific Purposes, 22, 153-176.

Chiang, W.-Y.; \& Duann, R. F. (2007). Conceptual metaphor for SARS: “war” between whom? Discourse \& Society, $18,579-602$.

Costa, T. (no prelo). O contexto pandémico no discurso mediático: diálogo(s) no uso da ironia e da metáfora. Pensardiverso. Revista de Estudos Lusófonos da Universidade da Madeira.

Covid-19 corpus. (2020). Engine Sketch. <https://www.sketchengine.eu/covid19/>.

Davis, M. (2020). The Coronavírus Corpus. English Corpora. <https://www.english-corpora.org/corona/>.

Gonzalez, G.; Hoyos, J.; \& Mendez, G. (2011). (H1N1) virus in Mexico: an approach via the print press. Comunicación y Sociedad, 16, 105-132.

Haddad, A.; \& Montero-Martínez, S. (2020). Covid-19: a metaphor-based neologism and its translation into Arabic. Journal of Science Communication, 1-21.

Johnson, M. (1987). The Body in the Mind: The Bodily Basis of Meaning, Imagination and Reason. Chicago: The University of Chicago Press.

Kort, S. (2017). Metaphor in Media Discourse: Representations of 'Arabs' and 'Americans' in American and Arab News Media. Dissertação de Doutoramento: University of Bristol .

Kovecses, Z.; Benczes, R.; Bokor, Z.; Csábi, S.; Lazányi, O.; \& Nucz, E. (2010). Metaphor: A practical introduction. Oxford: Oxford University Press.

Kwan, J. S.-L.; \& Lim, K. H. (2020). Understanding Public Sentiments, Opinions and Topics about Covid-19 using Twitter. IEEE/ACM International Conference on Advances in Social Networks Analysis and Mining. $<$ https://arxiv.org/abs/2012.03039>.

Lakoff, G.; \& Johnson, M. (1980). Metaphors We Live By. Chicago: The University of Chicago Press.

- (1999). Philosophy in the Flesh: The Embodied Mind and its Challenge to Western Thought. New York: Basic Books.

Muhammad, A.; Zhiyong, D.; Iram, A.; \& Nisar, M. (2020). Linguistic Analysis of Neologism related to Coronavirus (COVID-19). <https://papers.ssrn.com/sol3/papers.cfm?abstract_id=3608585>.

Nascimento, R. I.; \& Isquerdo, A. N. (2003). Frequência de palavras: um diagnóstico do vocabulário de redações de vestibular. Alfa, 47, 71-84.

Pinto, A.; \& Pereira, C. (2014). Modalização e construção do humor nas crónicas de Ricardo Araújo Pereira. REDIS: Revista de Estudos do Discurso, 3, 108-124.

Porfírio, J. (31 de maio de 2020). Covid-19: os três meses que mudaram tudo, dia a dia. Agência Lusa/Observador. <https://observador.pt/2020/05/31/covid-19-os-tres-meses-que-mudaram-tudo-dia-a-dia/>.

Rio-Torto, G. (2013). Léxico, Gramática e Processamento. In A. Almeida, E. Santos, \& J. Soledade (Eds.), O léxico em estudo (pp. 1-25). Bahia: EDUNEB. 
Rodrigues, A. D. (2015). Delimitação, Natureza e Funções do Discurso Mediático. In A. T. Peixinho, C. Camponez, I. Vargues, \& J. Figueira (Eds.), 200 Anos de Jornalismo contra a indiferença (pp. 33-46). Coimbra: Imprensa da Universidade de Coimbra.

Silva, A. S. (2006). O Mundo dos Sentidos em Português: Polissemia, Semântica e Cognição. Coimbra: Almedina.

. (2013). O que sabemos sobre a crise económica, pela metáfora. Conceptualizações metafóricas da crise na imprensa portuguesa. Media \& Jornalismo, 22, 11-34.

Soares, A. P.; Iriarte, Á.; Almeida, J. J.; Simões, A.; Costa, A.; França, P.; \& Comesaña, M. (2014). Procura -PALavras (P-PAL): Uma Nova Medida de Frequência Lexical do Português Europeu Contemporâneo. Psicologia: Reflexão e Crítica, 27, 110-123.

Tan, K. H.; Woods, P.; Azman, H.; Abdullah, I.; Hashim, R.; Rahim, H.; \& Kosem, I. (2020). Covid-19 Insights and Linguistic Methods. 3L: The Southeast Asian Journal of English Language Studies, 26, 1-23.

Teixeira, C.; \& Oliveira, T. (2017). O poder da opinião. Análise comparada de comentários televisivos sobre política. REDIS: Revista de Estudos do Discurso, 6, 212-234.

Ulanska, T.; Kuzmanovska, D.; Todorova, M.; \& Kirova, S. (2020). Extra linguistic factors behind lexical change in Modern English, Spanish and German. In L. G. Chova, A. L. Martínez, \& I. C. Torres (Eds.), INTED 2020 Proceedings (pp. 2307-2311). Spain: IATED Academy.

Vessey, R. (2017). Corpus Approaches to Language Ideology. Applied Linguistics, 38, 277-296.

Vigário, M.; Frota, S.; Martins, F.; \& Cruz, M. (2012). Frequência na Fonologia do Português: recursos e aplicações. In A. Costa, \& I. Duarte (Eds.), Nada na linguagem lhe é estranho. Estudos em homenagem a Isabel Hub Faria (pp. 613-631). Porto: Edições Afrontamento.

\section{Fontes do Corpus}

(março de 2019). Telejornal RTP, edições dos dias: $01 ; 03 ; 06 ; 10 ; 16 ; 18 ; 20 ; 22 ; 24 ; 26 ; 28 ; 31$ https://www.rtp.pt/play/p5272/e392942/telejornal

(março de 2020). Telejornal RTP, edições dos dias: $01 ; 02 ; 03 ; 04 ; 06 ; 08 ; 10 ; 12 ; 14 ; 16 ; 18 ; 20 ; 23 ; 25 ; 27 ; 29 ; 31$ https://www.rtp.pt/play/p6559/e462377/telejornal 
